\title{
The Democratization of Dental Implants for General Dentistry
}

Howard Katz

President of Dentox, San Diego CA, USA

\section{Retraction Note:}

The review article entitled "The Democratization of Dental Implants for General Dentistry" was submitted for peer-review process to Pharmaceutical Regulatory Affairs: Open Access on December 12, 2012. It was accepted on December 27, 2012, and published in Pharmaceutical Regulatory Affairs: Open Access on December 31, 2012.

From time to time, an author may wish to withdraw a manuscript after submitting it. Changing one's mind is an author's prerogative. An author is free to withdraw an article at any point in time following the terms and conditions. The above-mentioned review article is withdrawn on the request of author. 